\title{
Towards timely diagnosis of symptomatic breast and cervical cancer in South Africa
}

The global cancer burden is projected to increase by $50 \%$ by 2030 and, disturbingly, most of the increase will occur in low- and middleincome countries. ${ }^{[1-4]}$ Unique features of cancer in Africa are the disproportionately high burden of cancers in women (56\%), the high proportion of infection-related cancers (30\% of all cancers), and the late stage at which cancer is diagnosed (e.g. $46 \%$ of breast cancer in South Africa (SA) is diagnosed at an advanced stage). ${ }^{[3-7]}$ Cancer stage is a measure of cancer growth and spread, with stage at presentation being an important prognostic factor. Earlier stage at presentation, enabling more opportunities for curative treatment and improved outcomes, is therefore an important goal in any comprehensive cancer care policy.

Despite the growing burden, cancer has received relatively low public health priority in sub-Saharan Africa (SSA). The tide is turning in SA. In 2013, the first Ministerial Advisory Committee on the Prevention and Control of Cancer was established. In 2018, the SA President announced the set-up of a National Cancer Campaign. The National Department of Health has identified breast and cervical cancer as priority diseases. In SA, breast cancer is the most commonly diagnosed cancer among women and cervical cancer is the leading cause of cancer death among women. ${ }^{[8,9]}$ In 2017, a new national breast cancer prevention and control policy was launched and the cervical cancer prevention policy was updated ${ }^{[10,11]}$ Both policies aim to reduce incidence and mortality rates and improve the quality of life of women in SA.

Despite screening programmes in high-income countries, the majority of cancers (85-90\%) are diagnosed on the basis of symptomatic presentation. ${ }^{[12]}$ Studies have shown that for symptomatic breast cancer a shorter time between the recognition of symptoms by women and the first medical consultation is associated with early-stage disease ${ }^{[13,14]}$ and better breast cancer survival. ${ }^{[15,16]}$ Further, a substantial proportion of advanced-stage breast cancer cases could be avoided if patients present within 1 month of detecting symptoms. ${ }^{[14]}$ SA does not have a national public sector mammography screening programme. Typically, women with breast symptoms self-present to primary healthcare facilities and are referred to secondary- or tertiary-level facilities if further diagnostic work-up and treatment are required. Minimising the interval between first recognition of symptoms by women and the time of breast cancer diagnosis is dependent on timely presentation to primary healthcare providers by women with symptoms suggestive of breast cancer, appropriate assessment at the primary healthcare level, and good access to referral and treatment centres.

SA has had a national cervical cancer screening programme since 2001. However, population screening coverage remains suboptimal (current national coverage 57\% with marked provincial variation). ${ }^{[17]}$ Many women diagnosed with cervical cancer still present with latestage symptomatic disease (personal communication, Dr L van Wijk, Department of Radiation Oncology, Groote Schuur Hospital, Cape Town, 23 May 2018). Consequently, understanding processes related to cancer symptom awareness and behaviours is important in developing interventions to promote timely presentation of cervical cancer.

For both breast and cervical cancer there are subtle but important symptoms in early-stage disease, yet women often misinterpret these or wait until symptoms progress before they seek medical attention. Research has shown that cancer symptom awareness among the general population is low and that interventions to increase awareness lead to better outcomes. ${ }^{[18-20]}$ A study in Malaysia demonstrated that a public cancer awareness programme coupled with staff training reduced late-stage presentation of breast and cervical cancer by half over a 4 -year period. ${ }^{[19]}$

For people with potential symptoms of cancer, the journey to cancer diagnosis is complex and influenced by a multitude of factors including knowledge and awareness of cancer symptoms, symptom experiences, risk perception, and psychological, sociocultural and health system barriers to healthcare. ${ }^{[21-31]}$ The Model of Pathways to Treatment provides a useful research framework to understand patient journeys, as it takes into account the complicated and dynamic nature of help-seeking behaviour. ${ }^{[32,33]}$ By increasing understanding of the factors influencing the key events in the pathway to care, the model can be used to identify targets for interventions in order to encourage early detection, presentation and treatment. An important first research step is the development of culturally relevant and locally validated questionnaires to accurately measure symptom awareness and help-seeking behaviour in SA. A project being conducted in SA and Uganda and supported by the South African Medical Research Council, the Cancer Association of South Africa (CANSA) and the University of Cape Town is developing such a tool for use in SSA. Preliminary results are expected in late 2018 and will greatly assist with development and evaluation of local interventions.

In SA, the first presentation to the public health system is to primary healthcare providers, who play a pivotal role in cancer triage, possible diagnosis and referral. Studies from SA have shown that some cancer patients had visited primary level healthcare facilities several times before referral. ${ }^{[23,30]}$ Symptoms that could possibly be due to cancer are common, but most will not end up being cancer. ${ }^{[21]}$ A concern in the study by Moodley et al. ${ }^{[30]}$ was that women with comorbidities, who would have had greater contact with the primary healthcare services, had a longer diagnostic interval (time between first visit to a healthcare provider and time of diagnosis) compared with those without comorbidities. ${ }^{[30]}$ Understanding primary healthcare providers' knowledge of risk factors and symptoms as well as challenges faced in managing and referring patients with potential symptoms of breast symptoms could help identify potential targets for interventions to further reduce the diagnostic interval.

Various forms of support to primary healthcare providers exist internationally. Electronic risk assessment tools (RATs) are being evaluated in the UK, ${ }^{[34,35]}$ and as SA develops electronic medical records and databases at multiple levels of the health system, it would be important to ensure that databases include variables relevant to the development of local RATs. Mobile technology support, educational/ training interventions and specialist outreach visits should also be explored and evaluated. Importantly, we also need to better understand the role of traditional healers in the pathways to cancer diagnosis and include them in awareness and other educational and training interventions.

Factors influencing the time from first primary healthcare provider visit to cancer diagnosis include referral and diagnostic services organisation; waiting times for appointments, tests and assay results; availability of pathology and laboratory services; and the financial impact on patients (e.g. time off work and transport costs). ${ }^{[21]}$ The SA national breast cancer policy plan ${ }^{[10]}$ is developing and expanding specialised breast units at regional level to have multidisciplinary capability for diagnosis and basic surgical management, and support from tertiary provincial oncology units. This support could 
assist with rapid referral and decrease unnecessary delays. For timely diagnosis of symptomatic cervical cancer, establishing and expanding colposcopy services at secondary level will be important. Establishment of an electronic booking system could assist with appointments, referrals and feedback.

Achieving earlier diagnosis of symptomatic breast and cervical cancer is an important step in reducing the morbidity and mortality from these diseases. Potential improvements in timely diagnosis of breast and cervical cancer are possible with the implementation of evidence-based interventions, through a better-informed population and with a strengthened health system.

Funding. Research reported in this article was supported by CANSA, the University of Cape Town and the SA Medical Research Council with funds received from the SA National Department of Health, GlaxoSmithKline $\mathrm{R} \& \mathrm{D}$, the UK Medical Research Council and the UK government's Newton fund.

\section{J Moodley}

Cancer Research Initiative, Faculty of Health Sciences, University of Cape Town, South Africa; Women's Health Research Unit, School of Public Health and Family Medicine, Faculty of Health Sciences, University of Cape Town, South Africa; and South African Medical Research Council Gynaecology Cancer Research Centre, Faculty of Health Sciences, University of Cape Town, South Africa jennifer.moodley@uct.ac.za

\section{F M Walter}

Primary Care Unit, Department of Public Health and Primary Care, University of Cambridge, UK

\section{S E Scott}

Division of Population and Patient Health, King's College London Dental Institute, UK

\section{A M Mwaka}

Department of Medicine, School of Medicine, College of Health Sciences, Makerere University, Kampala, Uganda

\footnotetext{
1. Torre LA, Bray F, Siegel RL, Ferlay J, Lortet-tieulent J, Jemal A. Global cancer statistics: 2012. CA Cancer J Clin 2015;65(2):87-108. https://doi.org/10.3322/caac.21262

2. Ferlay J, Soerjomataram I, Dikshit R, et al. Cancer incidence and mortality worldwide: Sources, methods and major patterns in GLOBOCAN 2012. Int J Cancer 2015;136(5):E359-E386. https://doi. org/10.1002/iic. 29210

3. McCormack VA, Schüz J. Africa’s growing cancer burden: Environmental and occupational contributions. Cancer Epidemiol 2012;36(1):1-7. https://doi.org/10.1016/.canep.2011.09.005

4. Jemal A, Bray F, Forman D, et al. Cancer burden in Africa and opportunities for prevention. Cancer 2012;118(18):4372-4384. https://doi.org/10.1002\%2Fcncr.27410

5. Parkin DM, Nambooze S, Wabwire-Mangen F, Wabinga HR. Changing cancer incidence in Kampala, Uganda, 1991 - 2006. Int J Cancer 2010;126(5):1187-1195. https://doi.org/10.1002\%2Fijc.24838

6. McCormack VA, Joffe M, van den Berg E, et al. Breast cancer receptor status and stage at diagnosis in over 1,200 consecutive public hospital patients in Soweto, South Africa: A case series. Breast Cancer Res 2013;15(5):R84. https://doi.org/10.1186\%2Fbcr3478

7. Stewart TS, Moodley J, Walter FM. Population risk factors for late-stage presentation of cervical cancer in sub-Saharan Africa. Cancer Epidemiol 2018;53:81-92. https://doi.org/10.1016\%2Fj. canep.2018.01.014
}

8. South African National Cancer Registry. Cancer in South Africa 2014. Johannesburg: NCR, 2018. http://www.ncr.ac.za (accessed 30 May 2018)

9. Statistics South Africa. Mortality and cases of death in South Africa 2016. Johannesburg: Stats SA, 2018. http://www.statssa/goc/za (accessed 30 May 2018).

10. National Department of Health, South Africa. Breast Cancer: Prevention and Control Policy. Pretoria: $\mathrm{NDoH}, 2017$

11. South African National Department of Health. Cervical Cancer Prevention and Control Policy. Pretoria: $\mathrm{NDoH}, 2017$

12. Hamilton W. Cancer diagnosis in primary care. Br J Gen Pract 2010;60(571):121-128. https://doi. org/10.3399\%2Fbjgp 10x483175

13. Neal RD, Tharmanathan $P$, France $B$, et al. Is increased time to diagnosis and treatment in symptomatic cancer associated with poorer outcomes? Systematic review. Br J Cancer 2015;112(S1):S92-107. https:// doi.org/ $10.1038 \% 2 \mathrm{Fbjc} .2015 .48$

14. Arndt V, Stürmer T, Stegmaier C, Ziegler H, Dhom G, Brenner H. Patient delay and stage of diagnosis among breast cancer patients in Germany: A population based study. Br J Cancer 2002;86(7):10341040. https://doi.org/10.1038/si.bjc.6600209

15. Richards M, Westcombe A, Love S, Littlejohns $P$, Ramirez A. Influence of delay on survival in patients Richards M, Westcombe A, Love S, Littlejohns P, Ramirez A. Influence of delay on survival in patients
with breast cancer: A systematic review. Lancet 1999;353(9159):1119-1126. https://doi.org/10.1016\% $2 \mathrm{Fs} 0140-6736 \% 2899 \% 2902143-1$

16. Sainsbury R, Johnston C, Haward B. Effect on survival of delays in referral of patients with breastcancer symptoms: A retrospective analysis. Lancet 1999;353(9159):1132-1135. https://doi.org/10.1016 $\% 2 \mathrm{Fs} 0140-6736 \% 2899 \% 2902374-0$

17. Day C, Gray A. Health and related indicators. In: Padarath A, Barron P, eds. South African Health Review 2017. Durban: Health Systems Trust, 2017.

18. Robb K, Stubbings S, Ramirez A, et al. Public awareness of cancer in Britain: A population-based survey of adults. Br J Cancer 2009;101(S2):S18-S23. https://doi.org/10.1038\%2Fsj.bjc.6605386

19. Devi B, Tang T, Corbex M. Reducing by half the percentage of late-stage presentation for breast and cervix cancer over 4 years: A pilot study of clinical downstaging in Sarawak, Malaysia. Ann Oncol 2007;18(7):1172-1176. https://doi.org/10.1093\%2Fannonc\%2Fmdm105

20. O’Mahony $\mathrm{M}$, Comber $\mathrm{H}$, Fitzgerald $\mathrm{T}$, et al. Interventions for raising breast cancer awareness in women. Cochrane Database Syst Rev 2017, Issue 2. Art. No.: CD011396. https://doi.org/10.1002\%2F14651858. cd011396.pub2

21. Rubin G, Berendsen A, Crawford SM, et al. The expanding role of primary care in cancer control. Lancet Oncol 2015;16(12):1231-1272. https://doi.org/10.1016\%2Fs $1470-2045 \% 2815 \% 2900205-3$

22. Mwaka AD, Okello ES, Wabinga H, Walter FM. Symptomatic presentation with cervical cancer in Uganda: A qualitative study assessing the pathways to diagnosis in a low-income country. BMC Womens Health 2015;15(1):1-13. https://doi.org/10.1186\%2Fs12905-015-0167-4

23. Moodley J, Cairncross L, Naiker T, Momberg M. Understanding pathways to breast cancer diagnosis among women in the Western Cape Province, South Africa: A qualitative study. BMJ Open 2016;6(1):e009905. https://doi.org/10.1136\%2Fbmjopen-2015-009905

24. Dye TD, Bogale S, Hobden C, Tilahun Y, Deressa T, Reeler A. Experience of initial symptoms of breast cancer and triggers for action in Ethiopia. Int J Breast Cancer 2012;2012:1-5. https://doi. org $/ 10.1155 \% 2 \mathrm{~F} 2012 \% 2 \mathrm{~F} 908547$

25. Sharma K, Costas A, Shulman LN, Meara JG. A systematic review of barriers to breast cancer care in developing countries resulting in delayed patient presentation. J Oncol 2012;2012:1-8. https://doi. org $/ 10.1155 \% 2 \mathrm{~F} 2012 \% 2 \mathrm{~F} 121873$

26. Jassem J, Ozmen V, Bacanu F, et al. Delays in diagnosis and treatment of breast cancer: A multinational analysis. Eur J Public Health 2014;24(5):761-767. https://doi.org/10.1093\%2Feurpub\%2Fckt131

27. Poum A, Promthet S, Duffy SW, Parkin DM. Factors associated with delayed diagnosis of breast cancer in Northeast Thailand. J Epidemiol 2014;24(2):102-108. https://doi.org/10.2188\%2Fjea.je20130090

28. Whitaker KL, Macleod U, Winstanley K, Scott SE, Wardle J. Help seeking for cancer 'alarm' symptoms: A qualitative interview study of primary care patients in the UK. Br J Gen Pract 2015;65(631):e96-e105. https://doi.org/10.3399/bjgp15X683533

29. Salih AM, Alfaki MM, Alam-Elhuda DM, Nouradyem MM. Factors delaying presentation of Sudanese breast cancer patients: An analysis using Andersen's model. Asian Pacific J Cancer Prev 2016;17(4):2105-2110. https://doi.org/10.7314/APJCP.2016.17.4.2105

30. Moodley J, Cairncross L, Naiker T, Constant D. From symptom discovery to treatment: Women's pathways to breast cancer care: A cross-sectional study. BMC Cancer 2018;18(1):312. https://doi, org/10.1186/s12885-018-4219-7

31. Alves Soares Ferreira N, Melo Figueiredo de Carvalho S, Engrácia Valenti V, et al. Treatment delays among women with breast cancer in a low socio-economic status region in Brazil. BMC Womens Health 2017;17(1):13. https://doi.org/10.1186\%2Fs12905-016-0359-6

32. Walter F, Webster A, Scott S, Emery J. The Andersen model of total patient delay: A systematic review of its application in cancer diagnosis. J Health Serv Res Policy 2012;17(2):110-118. https://doi. org/10.1258\%2Fjhsrp.2011.010113

33. Scott SE, Walter FM, Webster A, Sutton S, Emery J. The model of pathways to treatment: Conceptualization and integration with existing theory. Br J Health Psychol 2013;18(1):45-65. https:// doi.org/10.1111\%2Fj.2044-8287.2012.02077.

34. Hamilton W, Green T, Martins T, Elliott K, Rubin G, Macleod U. Evaluation of risk assessment tools for suspected cancer in general practice: A cohort study. Br J Gen Pract 2013;63(606):e30-e36. https:// doi.org/10.3399\%2Fbjgp13x660751

35. Hippisley-Cox J, Coupland C. Symptoms and risk factors to identify women with suspected cancer in primary care: Derivation and validation of an algorithm. Br J Gen Pract 2013;63(606):11-21. https:// doi.org/10.3399\%2Fbjgp13x660733

S Afr Med J 2018;108(10):803-804. DOI:10.7196/SAMJ.2018.v108i10.13478 